\title{
A PARTICIPAÇÃO POPULAR EM SAÚDE: UMA ANÁLISE DAS LEIS ORGÂNICAS DOS MUNICÍPIOS DA REGIÃO CARBONÍFERA - SANTA CATARINA
}

\author{
R. S. VIEIRA ${ }^{1}$, T. F. HIJAZ ${ }^{2}$ \\ ${ }^{1,2}$ Universidade do Extremo Sul Catarinense \\ prof.reginaldovieira@gmail.com ${ }^{1}$
}

Submetido 04/05/2016 - Aceito 10/08/2018

DOI: $10.15628 /$ holos.2018.4064

\section{RESUMO}

Este artigo analisa se e como as Leis Orgânicas dos Municípios da Associação dos Municípios da Região Carbonífera (AMREC) trataram da participação popular em saúde, promovendo, no âmbito municipal, a universalização do direito à saúde, na esteira do prescrito na CRFB/1988 e de acordo com a concepção de República Participativa que o texto constitucional de 1988 preceituou. A primeira parte da pesquisa é teórica, com aplicação das técnicas de pesquisa bibliográfica e documental-legal. Já a segunda etapa é qualitativa e consiste na análise das Leis Orgânicas dos Municípios que compõem a AMREC, frente ao disposto pela Constituição da República Federativa do Brasil de 1988 no que diz respeito ao princípio da participação popular em saúde. A análise dos dados coletados demonstrou que, pelo menos formalmente, os municípios da Região Carbonífera inseriram em suas Leis Orgânicas a participação popular em saúde, respeitando o prescrito pelo texto constitucional.

PALAVRAS-CHAVE: Direito à saúde, participação popular em saúde, cidadania participativa, República participativa, Lei Orgânica Municipal.

\section{POPULAR PARTICIPATION IN HEALTH: AN ANALYSIS OF THE ORGANIC LAW OF MUNICIPALITIES OF THE REGION COAL - SANTA CATARINA}

\section{ABSTRACT}

This article examines whether and how the Municipal Organic Laws of the Association of Municipalities of the Coal Region (Associação dos Municípios da Região Carbonifera - AMREC) dealt with the popular participation in health, promoting, at the municipal level, the universal right to health as prescribed in the CRFB/1988 and according to the conception of the Participatory Republic that the Constitution stipulated in 1988. The first part of the research is theoretical, applying the techniques of bibliographic and documentary-legal search. The second part is qualitative
\end{abstract}

and consists in analyzing the Organic Laws of the municipalities that are part of AMREC, compared to the provisions of the Constitution of the Federative Republic of Brazil in 1988 concerning the principle of popular participation in health. The analysis of the data showed that, at least formally, the municipalities of the Coal Region inserted in their Organic Laws the popular participation in health, respecting the prescribed by the Constitution. 


\section{INTRODUÇÃO}

O direito fundamental à saúde é objeto de relevância no cenário das políticas públicas essenciais para o ser humano. Apesar de sua previsão normativa ao curso das Constituições brasileiras, foi somente com a Constituição da República Federativa do Brasil de 1988 que se incorporaram princípios e diretrizes capazes de garantir mecanismos de efetivação dos direitos declarados.

Uma dessas diretrizes é o da participação da comunidade, prevista expressamente na CRFB/1988, bem como na Lei no 8.080, de 19 de setembro de 1990, que veio regulamentar o Sistema Único de Saúde (SUS). Essa diretriz significa a possibilidade da participação popular da sociedade nos espaços de gestão das políticas públicas de saúde. Deve ser destacado que a expressão participação popular é aquela preponderantemente adotada nas Conferências Internacionais de Saúde, a exemplo da Carta de Otawa (1986), que indicam que a promoção da saúde não deve ser feita em um processo "sobre" e "para" o povo, mas deve ser construída "pelo" e "com" o povo (Vieira, 2013).

Em poucas palavras, a participação popular em saúde se consubstancia no controle social realizado pelos conselhos de direitos em saúde e pelas conferências de saúde, tendo por referência o modelo da cidadania participativa, opção teórica proposta para a presente pesquisa. Essa cidadania participativa, que constituiu o paradigma da República Participativa (Pilati, 2012; Vieira, 2013) inaugurado pela CRFB/1988 em seu artigo 1으, parágrafo único, rompe com o paradigma representativo. Assim, ao lado dos modelos de democracia representativa e semidireta, a sociedade pode exercer a sua cidadania a partir dos instrumentos da democracia participativa (Santos \& Avritzer, 2002; Bonavides, 2008).

Por outro lado, mediante as denominadas competências federativas, a CRFB/1988 definiu o papel de cada ente federativo no que diz respeito aos temas mais importantes para o País. Sobre a saúde, constata-se que o SUS é organizado em todos os entes federativos, sendo estes solidários na execução das políticas públicas de saúde. Atendo-se aos interesses da pesquisa, constata-se que entre as competências municipais está a de elaborar a sua Lei Orgânica Municipal, o que na prática se configura como uma Constituição Municipal.

Com base nessas premissas iniciais, surge a inquietação desta pesquisa, que consiste em investigar como as Leis Orgânicas dos Municípios da Associação dos Municípios da Região Carbonífera (AMREC), localizada no Sul do Estado de Santa Catarina, vieram a disciplinar a participação popular, promovendo, no âmbito municipal, o controle social como instrumento fundamental para a universalização do direito à saúde e a consolidação do Sistema único de Saúde, na esteira do prescrito na CRFB/1988 e de acordo com a concepção de República Participativa que o texto constitucional preceituou. 


\section{REVISÃO BIBLIOGRÁFICA}

2.1 A positivação do direito à saúde no ordenamento jurídico brasileiro e a participação popular em saúde

Com a Constituição da República Federativa do Brasil de 1988, o direito à saúde passou a ser reconhecido como um direito social fundamental (Piovesan, 2008; Cohn, 2009; Schwartz, 2001). Neste sentido, Dallari (1995, p. 23) confirma que "nenhum texto constitucional se refere explicitamente à saúde como integrante do interesse público fundante do pacto social até a promulgação da Carta de 1988".

Examinando o texto da CRFB/1988, verifica-se, inicialmente, que o direito à saúde se encontra previsto no artigo 60, de forma genérica, ao lado dos demais direitos sociais: "São direitos sociais a educação, a saúde, a alimentação, o trabalho, o transporte, a moradia, o lazer, a segurança, a previdência social, a proteção à maternidade e à infância, a assistência aos desamparados, na forma desta Constituição" (Brasil, 1988 - grifou-se).

Além disso, outras disposições são encontradas quando a CRFB/1988 determina que o dever de cuidar da saúde e da assistência é de competência comum da União, dos Estados, do Distrito Federal e dos Municípios, conforme se extrai do inciso II do artigo 23, bem como delimita, no inciso XII do artigo 24, a competência concorrente da União, dos Estados e do Distrito Federal para legislar sobre proteção e defesa da saúde (Brasil, 1988).

O constituinte originário, além de reconhecer o direito à saúde como um direito social fundamental, criou o Sistema Único de Saúde (SUS), bem como reservou uma seção específica sobre a matéria nos artigos 196 a 200. O SUS teve as suas bases formuladas ativamente pelo "movimento sanitarista", em especial na VIII Conferência Nacional de Saúde, que se materializou na constituinte da saúde (Cohn, 2009; Gerschman, 1995; Delduque \& Oliveira, 2009).

Nesse passo, o artigo 196 estabelece que a saúde é direito de todos e dever do Estado, garantido por meio de "políticas sociais e econômicas que visem à redução do risco de doença e de outros agravos e ao acesso universal e igualitário às ações e serviços para sua promoção, proteção e recuperação" (Brasil, 1988).

Comentando tal dispositivo constitucional, escreveu Grou (2008, p. 52):

O artigo 196 traz os princípios da universalidade e da igualdade. O Sistema Único de Saúde - SUS é universal, pois se destina a toda população, não apenas aos carentes ou aos que contribuem para a previdência social, mas a todos que precisarem - ou quiserem - de seus serviços de saúde. Por sua vez, a igualdade veda qualquer forma de discriminação no acesso e na prestação dos serviços de saúde.

No artigo 197, o texto constitucional refere que as ações e serviços de saúde são de relevância pública, cabendo ao Poder Público dispor sobre sua regulamentação, fiscalização e controle, devendo sua execução ser feita diretamente ou por meio de terceiros e, também, por pessoa física ou jurídica de direito privado (Brasil, 1988). 
De acordo com Ferraz e Benjamin (2010, p. 19), compreender as ações e serviços de saúde como "de relevância pública" significa que:

a) a saúde é direito público subjetivo exigível contra o Estado e contra todos os que, mesmo que entes privados, sob a chancela deste, a garantam;

b) a saúde é sempre assegurada através da atuação de uma função pública estatal, mesmo quando prestada por particulares, sendo que apenas as suas "ações e serviços" não têm exercício exclusivo do Estado; por isso mesmo são consideradas de relevância pública;

c) como função pública estatal, cabe ao Estado a direção da prestação de serviços e ações de saúde, devendo aquele fixar as diretrizes e parâmetros para o exercício destes; com isso, pode-se dizer que é limitada a liberdade dos prestadores privados;

d) as desconformidades nos serviços e ações permitem que o Estado exerça todo seu munus, inclusive com a utilização do instituto da desapropriação;

e) como direito público subjetivo, a saúde cria uma série de interesses na sua materialização, interesses esses que ora são tipicamente públicos, ora difusos, coletivos, individuais homogêneos ou individuais simples;

f) tais interesses, quando contrariados, dão legitimidade a uma série de sujeitos, públicos e privados, para buscarem, judicialmente, sua proteção (para tanto pode-se utilizar, além de outros estatutos, a Lei n. 7.347/85 e o Código de Defesa do Consumidor).

Além disso, na CRFB/1988, o Sistema Único de Saúde é caracterizado pela descentralização, com direção única em cada esfera de governo, pelo atendimento integral, com prioridade para as atividades preventivas, e pela participação da comunidade (art. 198 da CRFB/1988). O artigo 198 ainda estabelece que, tal qual a Previdência Social, há uma diversidade na base de financiamento do Sistema Único de Saúde, haja vista que contará com recursos do orçamento da seguridade social, da União, dos Estados, do Distrito Federal e dos Municípios, além de outras fontes (Brasil, 1988).

Dois anos após a promulgação da CRFB/1988, o Congresso Nacional aprovou a Lei Orgânica da Saúde - Lei no 8.080, de 19 de setembro de 1990 - a qual, segundo seu primeiro artigo, pretende regular, "em todo o território nacional, as ações e serviços de saúde, executados isolada ou conjuntamente, em caráter permanente ou eventual, por pessoas naturais ou jurídicas de direito público ou privado" (Brasil, 1990-A).

Desta feita, percebe-se que tanto a CRFB/1988 quanto a legislação pertinente ao tema em estudo consagraram o direito à saúde com destaque em seus respectivos textos, inovando, ainda, ao traçar diretrizes e princípios como a universalidade e a igualdade, atendimento integral, descentralização de gestão e participação popular, o que se caracterizou como um processo de democratização do direito à saúde, que passou a ser entendido como um direito (e dever) fundamental tutelado pela ordem jurídico-constitucional, que não prescinde da participação da sociedade em sua construção (Barroso, 2009; Piovesan, 2008; Vieira, 2013; Vieira, Hijaz \& Silvestre, 2011).

Essa democracia em saúde é uma expressão da democracia participativa (Balsemão, 2003; Vieira, 2013), constituindo-se como um dos pilares do SUS, e configurada na possibilidade de a sociedade participar do processo de definição e gestão das políticas públicas de saúde em instâncias colegiadas previstas em lei. 
Conforme Bonavides (2008), o exercício da democracia participativa, ao lado da democracia semidireta e da representativa, na esteira do disposto pela CRFB/1988, deve incluir de imediato a cidadania. Para ele a "democracia é o mais alto grau de legitimação do governo popular em nossa época" (Bonavides, 2008, p. 345).

Entende Weichert (2004, p. 171) que,

[...] como instrumento da democracia participativa, a participação social garante à população espaço direto na formulação, implementação, gestão e controle de uma política pública, afasta as práticas paternalistas e desenvolve o senso de responsabilidade comum.

Portanto, a concepção de democracia participativa em saúde adotada pelo texto constitucional veio romper com o modelo apenas representativo e eleitoral, e reconheceu a existência de um novo paradigma de cidadania participativa, que possibilita aos cidadãos influenciar as decisões do Estado, o da República Participativa, no qual existe a convivência da democracia representativa, da semidireta e da participativa (Pilati, 2012; Vieira, 2013).

A previsão legal das instâncias participativas em saúde ocorreu com a promulgação da Lei no 8.142/90, que regulamentou o artigo 198, III, da CRFB/1988. Em seu artigo 1ㅇ, a referida Lei dispõe que as Conferências e os Conselhos de Saúde são instâncias colegiadas do SUS:

Art. 1 O Sistema Único de Saúde (SUS), de que trata a Lei $n^{\circ} 8.080$, de 19 de setembro de 1990, contará, em cada esfera de governo, sem prejuízo das funções do Poder Legislativo, com as seguintes instâncias colegiadas:

I - a Conferência de Saúde; e

II - o Conselho de Saúde.

§ $1^{\circ}$ A Conferência de Saúde reunir-se-á a cada quatro anos com a representação dos vários segmentos sociais, para avaliar a situação de saúde e propor as diretrizes para a formulação da política de saúde nos níveis correspondentes, convocada pelo Poder Executivo ou, extraordinariamente, por esta ou pelo Conselho de Saúde.

$\S 2^{\circ}$ O Conselho de Saúde, em caráter permanente e deliberativo, órgão colegiado composto por representantes do governo, prestadores de serviço, profissionais de saúde e usuários, atua na formulação de estratégias e no controle da execução da política de saúde na instância correspondente, inclusive nos aspectos econômicos e financeiros, cujas decisões serão homologadas pelo chefe do poder legalmente constituído em cada esfera do governo. (Brasil, 1990-B)

Destaca Aguiar (2011, p. 55) que a Lei no 8.142/90 representa

[...] a garantia de um importante espaço público de controle social, mediante a participação da população nos conselhos e nas conferências de saúde, de modo a influir na gestão pública em relação à elaboração, ao controle e à fiscalização das políticas públicas.

O disposto da Lei no 8.142/90 foi regulado com base nas contribuições das conferências nacionais de saúde, pelo plenário do Conselho Nacional de Saúde e pela Resolução no 453/12, que estabeleceu "diretrizes para instituição, reformulação, reestruturação e funcionamento dos Conselhos de Saúde" (Brasil, 2012). 
Frisa-se que essas instâncias colegiadas e participativas se constituem em espaços de cogestão entre o Estado e a sociedade e devem ser criadas obrigatoriamente em todas as unidades da federação, ou seja, no âmbito federal, estadual, distrital e municipal. Tanto nos conselhos quanto nas conferências, a representação dos usuários do SUS e dos demais segmentos (gestores, trabalhadores da saúde e prestadores de serviços ao SUS) será paritária. Portanto, os usuários do SUS serão detentores de $50 \%$ dos espaços existentes nas conferências e nos conselhos de saúde.

Neste sentido, esse novo paradigma participativo indica que:

\begin{abstract}
A responsabilidade pela implementação do SUS é dos gestores, mas é papel da sociedade definir as diretrizes do Sistema nas Conferências de Saúde, assim como é responsabilidade dos Conselhos de Saúde zelar pelo seu cumprimento e deliberar sobre a implementação dessas políticas em seu nível de atuação. Acompanhar e fiscalizar a sua execução, inclusive sobre seu orçamento (Plano de Saúde, Lei de Diretrizes Orçamentárias, Lei Orçamentária Anual e Plano Plurianual) e sobre os gastos financeiros com saúde (analisar e aprovar a prestação de contas dos Fundos de Saúde, especialmente o Relatório de Gestão). [...] A participação da sociedade na implementação de políticas públicas é um bom indicador do grau de cidadania alcançado por uma determinada comunidade. (Rezente \& Trindade, 2003, p. 73)
\end{abstract}

Assim, neste novo modelo não existe um único detentor do caminho a ser trilhado na gestão das políticas públicas de saúde, mas ele deverá ser construído coletivamente a partir das forças sociais envolvidas no processo (Balsemão, 2003; Vieira, 2013).

Deve ser destacado também que, para os entes federativos receberem os repasses do Fundo Nacional de Saúde, é condição precípua que o conselho de saúde seja criado e esteja em funcionamento e organizado de forma paritária (Brasil, 1990-B).

Neste sentido, a sociedade precisa ocupar e atuar nesses espaços participativos, tendo em vista serem instâncias em construção. Sendo, desta forma,

[...] protagonista dos atos decisórios, para não correr o risco de as estruturas participativas, conquistadas na trajetória de redemocratização do Brasil após o regime ditatorial militar, virem a se converter em espaços cartoriais, de cumprimento de requisitos meramente formais para a transferência de recursos públicos, eivados de relações patrimonialistas e clientelistas. (Paganini \& Vieira, 2015, p. 338-339)

Outrossim, estas prerrogativas estabelecidas aos conselhos e às conferências de saúde na qualidade de diretriz fundamental da concepção de direito à saúde incorporada na CRFB/1988, devem ser observadas por todos os entes federativos, tendo por referência as denominadas competências federativas. Deste modo, no próximo tópico, portanto, analisam-se os principais aspectos pertinentes à divisão constitucional de competências, com foco na prerrogativa do ente federativo municipal para elaborar a sua Lei Orgânica.

\title{
2.2 A divisão constitucional de competências e a prerrogativa do município para elaborar a sua Lei Orgânica
}

A República Federativa do Brasil é "formada pela união indissolúvel dos Estados e Municípios e do Distrito Federal" (art. 1ㅇ, caput, da CRFB/1988). Na mesma esteira, observa-se 
que o artigo 18 do texto constitucional estabelece que "A organização político-administrativa da República Federativa do Brasil compreende a União, os Estados, o Distrito Federal e os Municípios, todos autônomos, nos termos desta Constituição" (Brasil, 1988).

Para este estudo, importa ressaltar que a competência comum material da União, dos Estados-membros, do Distrito Federal e dos Municípios foi fixada no artigo 23. De acordo com o dispositivo constitucional, é competência comum da União, dos Estados, do Distrito Federal e dos Municípios zelar pela guarda da Constituição, das leis e das instituições democráticas e conservar o patrimônio público, cuidar da saúde e assistência pública, da proteção e garantia das pessoas portadoras de deficiência, entre outros (Brasil, 1988).

Outrossim, o artigo 24 da CRFB/1988 trata da competência legislativa concorrente, cabendo à União a edição de normas gerais e aos Estados-membros e Distrito Federal a edição de normas suplementares. Segundo o inciso XII desse preceito constitucional, tanto a União quanto os Estados-membros e o Distrito Federal têm competência para legislar sobre temas referentes à proteção e defesa da saúde (Brasil, 1988).

De outro lado, observa-se que a CRFB/1988 reconheceu expressamente ao município a prerrogativa de elaborar a Lei Orgânica Municipal, conforme se depreende do caput do artigo 29:

O Município reger-se-á por lei orgânica, votada em dois turnos, com o interstício mínimo de dez dias, e aprovada por dois terços dos membros da Câmara Municipal, que a promulgará, atendidos os princípios estabelecidos nesta Constituição, na Constituição do respectivo Estado e os seguintes preceitos (Brasil, 1988).

Quanto à autonomia municipal, estabelece Tavares (2002, p. 743):

A Constituição Federal, rompendo toda discussão em torno do status do Município na organização do Estado brasileiro, declara, expressamente, que compõem a Federação e são dotados de autonomia. Realmente, nos arts. 1ำ, 18 e 34 fica certa a posição da comuna no Estado federal. Pelo art. 1ำ fica certo que a república brasileira é formada pela união indissolúvel dos Estados, Distrito Federal e Municípios. Pelo art. 18, a organização político-administrativa brasileira compreende a União, os Estados, o Distrito Federal e os Municípios. Pelo art. 34 há que ser reconhecida e assegurada a autonomia municipal.

Assim, aos municípios foi reconhecido o poder de auto-organização que, na prática, funciona como uma derivação do poder constituinte originário. Com efeito, ele se expressa nas suas leis orgânicas, limitadas tanto por princípios da Constituição Federal como da Constituição estadual. Feitas tais considerações, no próximo tópico passa-se a estudar como as Leis Orgânicas dos Municípios da Associação dos Municípios da Região Carbonífera (AMREC) disciplinaram a participação popular em saúde, tendo por referência o prescrito pela CRFB/1988.

\section{METODOLOGIA}

Nesta pesquisa, aplicou-se o método dedutivo, com a abordagem qualitativa, mediante consulta às Leis Orgânicas dos municípios que compõem a Associação dos Municípios da Região Carbonífera (AMREC), localizada no sul do Estado de Santa Catarina. A região (principalmente em 
seu principal município - Criciúma) teve historicamente um movimento social e sindical muito organizado, vinculado a defesa do Sistema Único de Saúde.

A AMREC é composta de doze municípios: Cocal do Sul, Criciúma, Forquilhinha, Içara, Lauro Müller, Morro da Fumaça, Nova Veneza, Orleans, Siderópolis, Treviso, Urussanga e Balneário Rincão, sendo que não existem municípios com grandes populações, tendo o mais populoso cerca 200.000 habitantes, e o menos populoso pouco mais de 3.500 habitantes (Associação dos Municípios da Região Carbonífera [AMREC], 2015).

O estudo teve por escopo investigar como as Leis Orgânicas dos Municípios da Associação dos Municípios da Região Carbonífera (AMREC) disciplinaram a participação popular em saúde, promovendo, no âmbito municipal, o controle como instrumento fundamental para a universalização do direito à saúde e para a consolidação do Sistema Único de Saúde, na esteira do prescrito na CRFB/1988 e de acordo com a concepção de República Participativa que o texto constitucional preceituou.

Justifica-se essa análise por ser no âmbito municipal que a participação popular tem o seu lócus principal (Dallari, 1998; Hermany, 2007), por ser onde o direito à saúde é exercido mais concretamente, tendo em vista a proximidade da realidade vivenciada pelo cidadão usuário do SUS.

A pesquisa foi realizada com $100 \%$ dos municípios que fazem parte da AMREC.

\section{RESULTADOS E DISCUSSÕES}

A análise e a interpretação dos dados qualitativos foram realizadas por meio da categorização, e posteriormente foi feita a análise das Leis Orgânicas, mediante o acesso a esses documentos nos sites dos municípios que compõem a AMREC, quais sejam, Balneário Rincão, Cocal do Sul, Criciúma, Forquilhinha, Içara, Lauro Müller, Morro da Fumaça, Nova Veneza, Orleans, Siderópolis, Treviso e Urussanga (AMREC, 2015).

Os resultados da pesquisa foram agrupados a partir do seguinte eixo: se e como os municípios da AMREC trataram o princípio da participação popular em saúde em suas Leis Orgânicas.

4.1 Se e como os municípios da AMREC trataram o princípio da participação popular em saúde em suas Leis Orgânicas

$\mathrm{Na}$ pesquisa realizada constatou-se que 100\% das Leis Orgânicas dos municípios investigados fazem referência ao direito à saúde e aos fundamentos organizacionais do SUS em seu texto. Entretanto, em alguns, isso foi feito apenas de forma superficial, enquanto em outros o legislador municipal, em consonância ao comando do texto constitucional de 1988 e das competências reconhecidas aos municípios, disciplinou a temática do direito à saúde com maior profundidade (Balneário Rincão, 2013; Cocal do Sul, 1995; Criciúma, 1990; Forquilhinha, 1990; Içara, 1990; Lauro Müller, 1990; Morro da Fumaça, 1990; Nova Veneza, 1990; Orleans, 2005; Siderópolis, 1990; Treviso, 1997; Urussanga, 1997). 
As informações coletadas demonstram que o legislador municipal, no momento da elaboração das leis orgânicas dos municípios da AMREC, fez uso da competência comum que lhe é conferida pelo texto constitucional, normatizando sobre o direito à saúde na qualidade de um direito fundamental de caráter social no principal documento legislativo municipal, de acordo com o disposto na CRFB/1988.

Verificou-se ainda que $75 \%$ das leis orgânicas dos municípios da amostra fazem previsão da participação popular em saúde, por meio das seguintes expressões: participação da comunidade, comissões de saúde, conselhos de saúde e conferências de saúde. Já $25 \%$ dos citados documentos legais apenas indicam que o município respeitará na execução de serviços de saúde o prescrito nos artigos 196 a 200 da CRFB/1988, o que indiretamente remete ao preceito da participação da comunidade na gestão do SUS, conforme dispõe o artigo 198, III, da CRFB/1988 (Brasil, 1988; Balneário Rincão, 2013; Cocal do Sul, 1995; Criciúma, 1990; Forquilhinha, 1990; Içara, 1990; Lauro Müller, 1990; Morro da Fumaça, 1990; Nova Veneza, 1990; Orleans, 2005; Siderópolis, 1990; Treviso, 1997; Urussanga, 1997).

Em relação aos municípios que trataram expressamente da participação popular em suas leis orgânicas, quatro deles (Morro da Fumaça, Nova Veneza, Siderópolis e Balneário Rincão) incluíram a expressão participação da comunidade (Balneário Rincão, 2013; Morro Da Fumaça, 1990; Nova Veneza, 1990; Siderópolis, 1990), sendo que destes, o de Balneário Rincão inseriu também no artigo 159, III, de sua Lei Orgânica Municipal: "[...] acesso do cidadão a informações da política municipal de saúde" (Balneário Rincão, 2013).

No que diz respeito aos conselhos de saúde, cinco dos municípios pesquisados, ou seja, 41,65\% reconheceram a existência do conselho de saúde em suas leis orgânicas (Balneário Rincão, 2013; Cocal do Sul, 1995; Criciúma, 1990; Forquilhinha, 1990; Içara, 1990; Lauro Müller, 1990; Morro da Fumaça, 1990; Nova Veneza, 1990; Orleans, 2005; Siderópolis, 1990; Treviso, 1997; Urussanga, 1997). Três dos municípios (Lauro Müller, Siderópolis e Criciúma) também citaram as conferências de saúde. Estes três municípios, além de terem inserido expressamente em suas leis orgânicas os conselhos e as conferências de saúde, também ressaltaram que tais instâncias participativas teriam caráter deliberativo (Lauro Müller, 1990; Siderópolis, 1990; Criciúma, 1990).

Portanto, todos os municípios cumpriram a obrigação constitucional e recepcionaram em seu texto legal a participação popular como um elemento necessário do Sistema Único de Saúde e do direito à saúde. Deste modo, acolheram no principal documento normativo municipal os postulados da cidadania participativa, reconhecidos pela CRFB/1988, ao recepcionar o paradigma da República Participativa (Pilati, 2012; Vieira, 2013).

Deve ser destacado que, apesar de não ser expressamente necessário que os municípios detalhem a forma como se dará o exercício da participação popular em saúde em suas leis orgânicas, tendo em vista já ser matéria tratada pela Lei no 8.142/90, quase metade deles trouxe os conselhos de saúde como instância desse espaço de cogestão da saúde entre o poder público e a sociedade (Balsemão, 2003; Vieira, 2013). Outro elemento que deve ser ressaltado é que $25 \%$ dos municípios, além de terem feito a previsão da existência das instâncias participativas em saúde dos conselhos e das conferências, fizeram constar em suas leis orgânicas que tais instâncias teriam caráter deliberativo, na esteira do prescrito pela Lei $n=8.142 / 90$. O caráter deliberativo é uma prerrogativa dos conselhos de saúde, conferida pela norma federal que significa que possuem 
capacidade de formular e decidir sobre a política pública de saúde e não apenas emitir opinião sobre ela.

Ressalte-se que o município de Criciúma conceitua, em sua lei orgânica, os conselhos e as conferências, no artigo 109, §§ 1으 e 2 을

§ 10 A Conferência Municipal de Saúde, convocada pelo Prefeito Municipal, com ampla representação comunitária, objetiva avaliar a situação do Município e fixar as diretrizes de política municipal de saúde.

§ 20 O Conselho Municipal de Saúde, com o objetivo de formular e controlar a execução da política municipal de saúde, inclusive nos aspectos econômicos e financeiros, será composto segundo a lei que dispuser sobre sua organização e funcionamento. (Criciúma, 1990)

Já a Lei Orgânica do Município de Forquilhinha, em consonância com o disposto na Lei no 8.142/90, reza, em seu artigo 110, que o Conselho Municipal de Saúde será "composto paritariamente por representantes de entidades prestadoras de serviços de saúde, população civil organizada e trabalhadores do Sistema Único de Saúde (SUS)" (Forquilhinha, 1990). Em Siderópolis, a Lei Orgânica prescreve em seu artigo 109, parágrafo único, que o Conselho Municipal de Saúde terá na sua composição, além daqueles segmentos citados em Forquilhinha, representante do Poder Executivo e do Poder Legislativo (Siderópolis, 1990).

Ora, o disposto na Lei Orgânica do Município de Siderópolis contém um equívoco na listagem dos segmentos que comporão o conselho municipal de saúde, tendo em vista incluir o Poder Legislativo, o que é vedado pela Lei $n$ o 8.142/90 e pela Resolução no 453/12 do Conselho Nacional de Saúde, além de ser incompatível com o previsto no artigo 2ㅇ da CRFB/1988, que estabelece que os Poderes Executivo, Legislativo e Judiciário são independentes e harmônicos (Brasil, 1988; Brasil, 1990; Brasil, 2012).

Portanto, sendo o conselho uma instância deliberativa e participativa, vinculada ao Poder Executivo, não é possível que um membro do Poder Legislativo atue nesse espaço no papel de conselheiro, considerando que entre as funções dos legisladores está a fiscalização e o controle dos atos do Poder Executivo.

Neste sentido, o Tribunal de Justiça da Paraíba decidiu, em julgamento da Ação Direta de Inconstitucionalidade no 999.2010.000853-4/001, impetrada pelo Ministério Público, pela inconstitucionalidade do artigo 163, § 2을 da Lei Orgânica do Município de Campina Grande - PB, que previa a participação de representante do Poder Legislativo na composição do Conselho Municipal de Saúde (Paraíba, 2011).

É importante registrar que a Resolução no 453/12 do Conselho Nacional de Saúde também veda a participação de membros do Ministério Público e do Poder Judiciário na composição dos conselhos municipais de saúde (Brasil, 2012), tendo em vista as atribuições que cada um deles possui no texto constitucional, as quais não possibilitam que estes sejam conselheiros de saúde. 


\section{CONCLUSÃO}

A CRFB/1988 reconheceu a saúde como direito fundamental e social, de caráter universal, rompendo com o caráter contributivo do modelo anterior. Nesse sentido, a saúde deixou de ser um benefício a ser recebido por aqueles que contribuíssem para o sistema, na qualidade de um seguro social, e se constituiu, a partir de então, como um direito de todos e uma obrigação do Estado.

No comando constitucional "obrigação do Estado" encontra-se a obrigação da prestação dos serviços de saúde por todos os entes federativos, cabendo aos usuários do SUS a provocação de qualquer um deles para ver o seu direito cumprido.

Nesse sentido, além do disposto na CRFB/1988 e nas leis federais que dispõe sobre as políticas públicas de saúde, cabe também aos entes federativos tratar sobre o assunto em suas disposições normativas.

Portanto, a partir das competências estabelecidas na CRFB/1988, possuem os municípios a prerrogativa de disporem em suas leis orgânicas e demais leis municipais sobre o direito à saúde, incluindo-se a participação popular em saúde e respeitando o previsto na CRFB/1988.

Como visto, a participação popular em espaços democráticos que tratam das matérias relacionadas à saúde faz parte da gênese do SUS e do próprio direito à saúde, tendo em vista serem estes uma criação da primeira, no processo de redemocratização do Brasil após a Ditadura Militar e da mobilização da sociedade pelo reconhecimento de direitos historicamente sonegados para a grande maioria do povo brasileiro.

Neste sentido, não existe direito à saúde e o SUS sem a participação da sociedade na gestão das políticas públicas de saúde (Vieira, 2013). Essa é a essência da concepção adotada na CRFB/1988, que reconheceu a cidadania participativa como um dos pilares do Estado Democrático de Direito inserto no texto constitucional.

E essa concepção participativa tem no âmbito municipal o seu contexto de maior concretização, em face da proximidade da realidade vivida pelos munícipes. Ademais, é no lócus municipal, principalmente nos municípios de pequeno e médio porte (tendo em vista o contingente populacional envolvido, bem como a área territorial) que as experiências da democracia participativa têm se efetivado.

Portanto, foi esse contexto que norteou a presente pesquisa e que definiu o recorte metodológico eleito. A coleta de dados feita nas leis orgânicas municipais demonstrou que, de uma forma geral, todos os doze municípios analisados tratam da saúde/direito à saúde e da participação popular em suas leis orgânicas, em respeito ao comando constitucional.

Especificamente sobre a participação popular em saúde, os artigos inseridos nas Leis Orgânicas dos municípios da Região Carbonífera permitem concluir que, pelo menos formalmente, houve o respeito ao paradigma da República Participativa que o texto constitucional de 1988 preceituou. Entretanto, somente com a análise das leis municipais que regularam o disposto nas Leis Orgânicas, do Regimento Interno e das atas de reunião dos conselhos municipais de saúde seria possível avaliar se, na prática o disposto nas Leis Orgânicas acerca da participação popular em saúde tem se concretizado no âmbito de cada município. 


\section{REFERÊNCIAS}

Aguiar, Z. N. (2011). SUS - Sistema único de saúde: antecedentes, percurso, perspectivas e desafios. São Paulo: Martinari.

Associação dos Municípios da Região Carbonífera. (2015). AMREC. Disponível em: <http://www.amrec.com.br/index/municipios-associados/codMapaltem/42512>. Acesso em: 28 de setembro de 2015.

BALNEÁRIO RINCÃO. (2013). Lei Orgânica do Município de Balneário Rincão, de 16 de dezembro de 2013. Balneário Rincão, SC. Disponível em: <https://leismunicipais.com.br/lei-organicabalneario-rincao-sc>. Acesso em: 25 de janeiro de 2016.

Balsemão, A. (2003). Competências e rotinas de funcionamento dos conselhos de saúde no Sistema Único de Saúde no Brasil. In: ARANHA, M. I. (Org.). Direito sanitário e saúde pública. (2 v., v. 1, pp. 301-318), Brasília: Ministério da Saúde.

Barroso, L. B. (2009). Da falta de efetividade à judicialização excessiva: direito à saúde, fornecimento gratuito de medicamentos e parâmetros para a atuação judicial. In: MARTEL, L. de C. V. (Org.). Estudos contemporâneos de direitos fundamentais. (pp. 309-335). Rio de Janeiro: Lumen Juris.

Bonavides, P. (2008). Teoria constitucional da democracia participativa: por um Direito Constitucional de luta e resistência - por uma nova hermenêutica - por uma repolitização da legitimidade. (3. ed). São Paulo: Malheiros.

BRASIL. (1988). Constituição da República Federativa do Brasil: atualizada até a Emenda Constitucional no 90, Brasília, DF, 05 de outubro de 1988. Disponível em: <http://www.planalto.gov.br/ccivil_03/Constituicao/ConstituicaoCompilado.htm>. Acesso em: 17 de dezembro de 2015.

BRASIL. (1990-A). Lei no 8.080, de 19 de setembro de 1990. Dispõe sobre as condições para a promoção, proteção e recuperação da saúde, a organização e o funcionamento dos serviços correspondentes e dá outras providências. Brasília, DF. Disponível em: <http://www.planalto.gov.br/ccivil_03/Leis/L8080.htm>. Acesso em: 17 de dezembro de 2015.

BRASIL. (1990-B). Lei no 8.142, de 28 de dezembro de 1990. Dispõe sobre a participação da comunidade na gestão do Sistema Único de Saúde (SUS) e sobre as transferências intergovernamentais de recursos financeiros na área da saúde e dá outras providências. Brasília, DF. Disponível em: <http://www.planalto.gov.br/ccivil_03/LEIS/L8142.htm>. Acesso em: 01 de fevereiro de 2016.

BRASIL. (2012). Conselho Nacional de Saúde. Resolução no 453, de 10 de maio de 2012. Disponível em: <http://bvsms.saude.gov.br/bvs/saudelegis/cns/2012/res0453_10_05_2012.html>. Acesso em: 01 de fevereiro de 2016.

COCAL DO SUL. (1995). Lei Orgânica do Município de Cocal do Sul, de 26 de setembro de 1995. Cocal do Sul, SC. Disponível em: <http://www.cocaldosul.sc.gov.br/legislacao/index/detalhes/cod Mapaltem/54900/codNorma/189260>. Acesso em: 25 de janeiro de 2016. 
Cohn, A. (2009). A reforma sanitária brasileira após 20 anos do SUS: reflexões. Cad. Saúde Pública, Rio de Janeiro, 25(7), pp. 1.614-1.619, recuperado em julho 2009. Disponível em: <http://www.scielo.br/scielo.php?script=sci_arttext\&pid=S0102-311X2009000700020>. Acesso em: 25 de janeiro de 2016.

CRICIÚMA. (1990). Lei Orgânica do Município de Criciúma, de 05 de julho de 1990. Criciúma, SC. Disponível em: <http://www.camaracriciuma.sc.gov.br/documento/lei-organica-municipal7807>. Acesso em: 25 de janeiro de 2016.

Dallari, S. G. (1995). Os estados brasileiros e o direito à saúde. São Paulo: Hucitec.

Dallari, S. G. (1988). O direito à saúde. Rev. Saúde Pública, São Paulo, v. 22, n. 1, p. 57-63, 1988.

DELDUQUE, M. C., \& OLIVEIRA, M. S. de C. (2009). Tijolo por tijolo: a construção permanente do direito à saúde. In: COSTA, A. B., SOUZA JR., J. G. de, DELDUQUE, M. C., OLIVEIRA, M. S. de C., \& DALLARI, S. G. (Org.). O direito achado na rua: introdução crítica ao direito à saúde [pp. 103112). Brasília: CEAD/ UnB.

FERRAZ, A. A. M. de C., \& BENJAMIN, A. H. V. (2010). O conceito de "relevância pública" na Constituição Federal. BDJur, Brasília, DF, 6 maio 2010. Disponível em: <http://bdjur.stj.jus.br/dspace/handle/2011/30603>. Acesso em: 25 de janeiro de 2016.

FORQUILHINHA. (1990). Lei Orgânica do Município de Forquilhinha, de 15 de novembro de 1990. Forquilhinha, SC. Disponível em: <https://leismunicipais.com.br/a1/lei-organica-forquilhinhasc>. Acesso em: 25 de janeiro de 2016.

GERSCHMAN, S. (1995). A democracia inconclusiva: um estudo da reforma sanitária brasileira. Rio de Janeiro: Fiocruz.

GROU, K. B. (2008). O acesso a medicamentos como direito humano fundamental. Dissertação de Mestrado em Direito. Pontifícia Universidade Católica de São Paulo, São Paulo.

HERMANY, R. (2007) (Re)discutindo o espaço local: uma abordagem a partir do direito social de Gurvitch. Santa Cruz do Sul: Edunisc/IPR.

IÇARA. (1990). Lei Orgânica do Município de Içara, de 05 de julho de 1990. Içara, SC. Disponível em: <https://leismunicipais.com.br/a1/lei-organica-icara-sc>. Acesso em: 25 de janeiro de 2016.

LAURO MÜLLER. (1990). Lei Orgânica do Município de Lauro Müller, de 05 de abril de 1990. Lauro Müller, SC. Disponível em: <http://www.lauromuller.sc.gov.br/uploads/264/arquivos/ 558408_LEI_ORGANICA_DE_LAURO_MULLER__Atualizada_ate_ELO_7_2012.pdf>. Acesso em: 25 de janeiro de 2016.

MORRO DA FUMAÇA. (1990). Lei Orgânica do Município de Morro da Fumaça, de 09 de abril de 1990. Morro da Fumaça, SC. Disponível em: <http://www.morrodafumaca.sc.gov.br/ legislacao/index/detalhes/codMapaltem/6452/codNorma/194894>. Acesso em: 25 de janeiro de 2016.

NOVA VENEZA. (1990). Lei Orgânica do Município de Nova Veneza, de 25 de abril de 1990. Nova Veneza, SC. Disponível em: <https://leismunicipais.com.br/a1/lei-organica-nova-veneza-sc>. Acesso em: 25 de janeiro de 2016.

ORLEANS. (2005). Lei Orgânica do Município de Orleans, de 12 de dezembro de 2005. Orleans, SC. Disponível em: <http://orleans.sc.gov.br/2013/index.php?option=com_content\&view=article 
\&id=109\&|temid=554>. Acesso em: 25 de janeiro de 2016 .

PAGANINI, J., \& VIEIRA, R de S. (2016). A cidadania participativa no Sistema Único de Assistência Social. HOLOS, [s.l.], 8, pp. 330-341, recuperado em janeiro 2016. Disponível em: <http://www2.ifrn.edu.br/ojs/index.php/HOLOS/article/view/3687/1332>. doi:http://dx.doi.org/10.15628/holos.2015.3687. Acesso em: 28 de janeiro de 2016.

PARAÍBA. (2011). Ação Direta de Inconstitucionalidade no 999.2010.000853-4/001. Autor: Ministério Público do Estado da Paraíba. Julgada em 31 de agosto de 2011. Paraíba. Disponível em: <http://www.tjpb.jus.br/pleno-defere-liminar-em-adin-e-veta-participacao-de-vereadorno-conselho-municipal-de-saude-de-cg>/. Acesso em: 01 de fevereiro de 2016.

PILATI, J. I. (2012). A propriedade e função social na pós-modernidade. (2. ed.). Rio de Janeiro: Lumen Juris.

PIOVESAN, F. (2008). Direitos humanos e o direito constitucional internacional. São Paulo: Saraiva.

REZENDE, C. A. P., \& TRINDADE, J. (2003). Manual da atuação jurídica em saúde pública. In: BRASIL. Ministério da Saúde. Direito sanitário e saúde pública. (v. II. pp. 13-154). Brasília: Ministério da Saúde.

SANTOS, B. de S., \& AVRITZER, L. (2002). Para ampliar o cânone democrático. In: SANTOS, Boaventura de Sousa (Org.). Democratizar a democracia: os caminhos da democracia participativa. (pp. 39-82). Rio de Janeiro: Civilização Brasileira.

SCHWARTZ, G. (2001). Direito à saúde: efetivação em uma perspectiva sistêmica. Porto Alegre: Livaria do Advogado.

SIDERÓPOLIS. (1990). Lei Orgânica do Município de Siderópolis, de 27 de abril de 1990. Siderópolis, SC. Disponível em: <http://www.camarasideropolis.sc.gov.br>. Acesso em: 25 de janeiro de 2016.

TAVARES, A. R. (2002). Curso de direito constitucional. (22. ed.) São Paulo: Saraiva.

TREVISO. (1997). Lei Orgânica do Município de Treviso, de 08 de julho de 1997. Treviso, SC. Disponível em: <http://camaradetreviso.sc.gov.br/index.php/legislacao-municipal/lei-organi ca.html>. Acesso em: 25 de janeiro de 2016.

URUSSANGA. (1997). Lei Orgânica do Município de Urussanga, de 09 de dezembro de 1997. Urussanga, SC. Disponível em: <https://leismunicipais.com.br/legislacao-municipal/4471/leisde-urussanga-sc>. Acesso em: 25 de janeiro de 2016.

VIEIRA, R. de S. (2013). A cidadania na república participativa: pressupostos para a articulação de um novo paradigma jurídico e político para os Conselhos de Saúde. Tese Doutorado em Direito, PPGD da Universidade Federal de Santa Catarina, Florianópolis, SC, Brasil.

VIEIRA, R. de S., HIJAZ, T. F., \& SILVESTRE, M. de S. (2011). Direito à saúde e atuação judicial: o fornecimento gratuito de medicamentos não inclusos nas listas oficiais do Sistema Único de Saúde (SUS). In: REIS, J. R. dos, LEAL, R. G., COSTA, M. M. M. da, \& LEAL, M. C. H. (Org.). As políticas públicas no constitucionalismo contemporâneo [v. 3, pp. 579-594]. Santa Cruz do Sul: Edunisc.

WEICHERT, M. A. (2004). Saúde e federação na Constituição brasileira. Rio de Janeiro: Lumen Juris. 